\title{
Educação feminina no século XIX: aproximações entre Honoré de Balzac e Norbert Elias
}

\author{
Feminine education in the 19th century: approaches between \\ Honoré de Balzac and Norbert Elias \\ Educación femenina en el siglo XIX: aproximaciones entre \\ Honoré de Balzac y Norbert Elias
}

\author{
TEREZINHA OLIVEIRA* \\ SANDRA REGINA FRANCHI RUBIM**
}

\begin{abstract}
RESUMO - Nesse texto faremos aproximações entre a literatura de Honoré de Balzac Memórias de Duas Jovens Esposas (1841) e a obra de Norbert Elias O Processo Civilizador (1939). Refletiremos sobre mudanças de comportamentos nas relações sociais entre a Nobreza de Espada e a Nobreza de Toga, na sociedade francesa do século XIX. Por meio do método histórico-social destacaremos alguns aspectos da educação feminina requerida nessa época. Em virtude dessas reflexões sobre as transformações nos comportamentos sociais, o conceito de 'humanização' presente em Aristóteles na Ética a Nicômaco e de Antonio Candido na obra Literatura e Sociedade: estudos de teoria e história literária torna-se essencial para nossa abordagem, já que entendemos que as mudanças sociais ocorrem na história, em decorrências das ações das pessoas.
\end{abstract}

Palavras-chave - Educação feminina. Literatura. Civilização.

\begin{abstract}
In this paper we will make links between the literature of Honoré de Balzac's Memoirs of Two Young Wives (1841) and the work of Norbert Elias' The Civilizing Process (1939). We reflect on behavioral changes in social relations between the Sword nobility and the Toge Nobility in French society of the early nineteenth century. Through the social-historical method we will highlight some aspects of female education required at this time. Because of these reflections on the changes in social behavior, the concept of 'humanization' present in Aristotle in the Nicomachean Ethics and in the work of Antonio Candido, Literature and Society: Studies theory and literary history, become essential to our approach, since we understand that social changes occur in history as derivations of people's actions.
\end{abstract}

Keywords - Feminine education. Literature. Civilization.

RESUMEN - En este artículo vamos a establecer vínculos entre la literatura de Honoré de Balzac Memorias de dos jóvenes recién casadas (1841) y la obra de Norbert Elías El proceso de la civilización (1939). Reflexionaremos sobre cambios de conductas en las relaciones sociales entre la Nobleza de Espada y la Nobleza de Toga, en la sociedad francesa del siglo XIX. A través del método histórico-social destacaremos algunos aspectos de la educación femenina requerida en esa época. Debido a estas reflexiones sobre las transformaciones en las conductas sociales, el concepto de 'humanización' presente en Aristóteles en la Ética a Nicómaco y de Antonio Candido en la obra Literatura y Sociedad: estudios de teoría e historia literaria se convierte en esencial para nuestro enfoque, ya que entendemos que los cambios sociales se producen en la historia, en consecuencia de las acciones de la gente.

Palabras clave - Educación femenina. Literatura. Civilización.

\footnotetext{
* Doutora em História pela Universidade Estadual Paulista Júlio de Mesquita Filho (Araçatuba, SP, Brasil) e Professora na Universidade Estadual de Maringá (Maringá, PR, Brasil).E-mail: <teleoliv@gmail.com>.

**Doutoranda em Educação pela Universidade Estadual de Maringá (Maringá, PR, Brasil).E-mail: <srfrubim@gmail.com>.
} 


\section{INTRODUÇÃO}

Participar das refeições sentados à mesa, fazer uso do garfo e faca, tomar banho, o que existe de mais natural do que isso, ou de mais cultural? Mas, como os homens se tornaram educados, começaram a tratar-se com boas maneiras, passaram a seguir determinadas regras comportamentais no público e no privado? Como esse processo ocorreu? Como essas mudanças atuaram sobre as relações entre as pessoas?

As respostas a essas perguntas intrigantes estão na obra O Processo Civilizador de Norbert Elias (18971990). Nessa obra, ele analisa os efeitos da formação do Estado Moderno na Europa sobre os costumes e a moral dos indivíduos. Norbert Elias, buscando informações em livros de etiquetas e boas maneiras desde o século XIII até o seu presente, percebe que nossos hábitos encontramse sempre atrelados a um determinado tempo histórico, aquele das diversas épocas históricas.

Renato Janine Ribeiro, em sua Apresentação a Norbert Elias explicita que a intenção deste pensador foi elaborar a teoria do "[...] desenvolvimento dos modos de conduta, a 'civilização dos costumes' [...]”, (ELIAS, 1994, p. 10). Habituamo-nos a imaginar que certa maneira de agir é melhor porque expressa melhor a natureza humana. Segundo Elias (1994) isso não procede. Para ele, o que ocorreu foi um condicionamento e um adestramento; não existe atitude natural no homem. Desde a Idade Média, em que o domínio das pulsões era bastante reduzido, até aos nossos dias, a elite dirigente foi, pausadamente, modelada pelas teias de interdependências da vida social, e a espontaneidade deu lugar à regra e à coibição na vida privada.

Este pensador acentua que as mudanças nos costumes se desenvolvem continuamente, implicando modificações na constituição psíquica do homem. Para Elias (1994), esses fenômenos sociais e psíquicos podem ser desvendados com maior clareza na história da conduta diária. Assim, ele formula também uma teoria do desenvolvimento social e psíquico da civilização.

Em face dessas considerações pretendemos, nesse texto, tecer algumas aproximações entre o romance Memórias de Duas Jovens Esposas, de Honoré de Balzac (1799-1850), e o processo civilizador de Norbert Elias. Segundo Paulo Rónai (1989, p. 20), na sua biografia sobre o romancista da Restauração, este foi o "[...] criador do gênero mais importante da literatura moderna, o romance de costumes". Rónai (1989) afirma que o próprio Balzac nomeia seus romances como história dos costumes. O romance eleito está inserido na obra balzaquiana $A$ Comédia Humana. ${ }^{1}$

Neste texto, ao relacionar a literatura de Balzac com a obra de Elias O Processo Civilizador, analisaremos certas mudanças de comportamentos nas relações sociais entre a Nobreza de Espada e a Nobreza de Toga ${ }^{2}$ em especial, as transformações ocorridas na educação feminina. Ressaltamos, pois, que embora a França, no século XIX, fosse burguesa, eram os valores aristocráticos que nela predominavam.

Consideramos que as demandas sociais de cada tempo histórico possibilitam transformações nos hábitos e costumes, socialmente aceitos. Simples atos cotidianos como os de alimentar-se e vestir-se são aprendidos pelo homem por meio do ato educativo, o que implica a convivência social. Nesse sentido, a educação permite a apropriação de costumes, hábitos e valores e, também, possibilita mudanças nos comportamentos dos indivíduos inseridos em dada época histórica. Essas transformações contínuas na 'nas ações das pessoas' oportunizaram a atual condição de civilização e de desenvolvimento do nosso tempo. A totalização dessas transformações, segundo Elias (1994), possibilitou a constituição da atual civilização.

Nesses termos, tendo em vista a complexidade das teias que envolvem os homens, nos tempos atuais adotamos como campo teórico-metodológico a História da Educação e a História Social. A História Social oferece-nos oportunidade de se compreender as produções humanas como resultantes das múltiplas vinculações articuladas pela dinâmica social e não da ação de indivíduos isolados, independentes do contexto que os cerca. Condizente com esse pensamento, reportamo-nos a Castro (1997, p. 54) que caracteriza a História Social " [...] enquanto forma de abordagem que prioriza a experiência humana e os processos de diferenciação e individuação dos comportamentos e identidades coletivos - sociais na explicação histórica". Não é o ser humano isolado em um único instante que importa, mas sim o ser humano e as relações sociais, bem como seus modos de sentir e pensar.

Observamos, assim, que o enfoque educacional nesse estudo, está relacionado ao entendimento de que a Educação ocorre e perpassa as relações sociais, como uma exigência de formação do homem para a vida em sociedade. Em face dessa percepção da educação e da história, acreditamos que a literatura possibilita o desenvolvimento do espírito de urbanidade no homem. A humanização, aqui aludida, refere-se ao processo que forma no homem traços fundamentais para a sua construção como ser social, por conseguinte, referimonos a educação.

A definição de Antonio Candido (1995, p. 249) explicita o nosso entendimento de humanização:

Entendo aqui humanização [...] o processo que confirma no homem aqueles traços que reputamos essenciais, como o exercício da reflexão, a aquisição do saber, a boa disposição para com o próximo, o afinamento das emoções, a capacidade de penetrar nos problemas da 
vida, o senso da beleza, a percepção da complexidade do mundo e dos seres, o cultivo do humor. A literatura desenvolve em nós a quota de humanidade na medida em que nos torna mais compreensivos e abertos para a natureza, a sociedade, o semelhante.

Apreendemos, mediante esse excerto, que a Educação, em todos os períodos da História, procura abrir caminhos que possibilitem novos horizontes para a formação humana.

Postulamos, enfim, que a contribuição das artes e conhecimentos produzidos pelos homens, portanto, não somente a Educação institucionalizada ou História, mas também a da literatura, da poesia, se faz indispensável para o processo de educação e humanização do homem. Sob a perspectiva da formação do ser humano, entendemos a educação como uma prática social, que busca realizar nos sujeitos o processo de humanização. Exatamente por isso ela precisa ser ensinada, dirigida pedagogicamente, de forma intencional.

Aristóteles, nesse sentido, na obra Ética a Nicômaco, entende o homem como um ser social e político, nascido para a vida em comum. Assim, toda a ação humana está orientada para a execução de algum bem, ao qual estão unidos o bem e a felicidade. Por sua própria natureza os homens buscam o bem e a felicidade; esta busca poderia ser possibilitada pela virtude, entendida como Aretê excelência. Por meio do nosso caráter podemos atingir a excelência. A boa conduta, a força do espírito, a força da vontade guiada pela razão pode nos levar à excelência moral. Essa excelência, leia-se ética, é o caminho que dirige o homem para a felicidade. Dessa forma, a felicidade está relacionada a uma sabedoria prática, que se traduz em escolhas que convergem para o bem social. Convivendo em sociedade, o homem precisa buscar o conhecimento (virtude intelectual) e praticar a justiça (virtude moral) para deliberar sobre o seu agir, de modo que suas ações sejam deliberadas, conscientemente, para si e para o outro. Portanto, por meio dos atos que praticamos nas relações com os outros, tornamo-nos justos ou injustos, pois os atos bons levam à virtude e os atos maus levam ao vício. Por isso, como afirma o filósofo: “[...] É preciso, pois, atentar para a qualidade dos atos que praticamos, porquanto da sua diferença se pode aquilatar a diferença de caracteres" (ARISTÓTELES, Ética a Nicômaco, L. II, c. 1, 1103b). O nosso conceito de humanização, portanto, vincula-se ao conceito de educação como um fenômeno social que se legitima quando imprime no homem determinados comportamentos que o credencia a viver em sociedade.

Desse modo, nossa análise refletirá, primeiramente, sobre a possibilidade da literatura como fonte e objeto de estudo e, em seguida, consideraremos a relevância dos estudos fundamentados nos clássicos para a formação humana. Tendo como pressuposto esses dois eixos norteadores buscaremos mapear as mudanças de comportamento nas relações sociais entre a Nobreza de Espada e a Nobreza de Toga, na França do século XIX, como condição de desenvolvimento e conservação dos indivíduos e da sociedade.

\section{A literatura CLÁSSICA COMO FONTE}

Assistimos, hoje, à expansão e à consolidação de estudos, de obras clássicas, focados na compreensão da sociedade, dos homens e do processo educativo. Constatamos a relevância de olharmos para o passado, querer e reconhecer, nas primeiras civilizações, as nossas raízes. É inquestionável o entendimento de que somos história, partimos de algo e que, portanto, esse algo precisa ser conhecido. Consideramos que a História se apresenta como fonte de conhecimento e exemplo de ações dos homens em outros tempos. Percebe-se, assim, a possibilidade de aprendermos com as experiências do outro, acumular vivências que nos capacitem no presente. Não como imitação, mas, sim, vistas como subsídios para abordarmos as questões atuais com mais discernimento.

Reconhecemos, assim, o caráter educativo da História no que concerne à formação do homem contemporâneo, porque ela nos dá um leque de possibilidades que amplia o nosso olhar para a realidade. Dessa forma, destacamos a importância da leitura dos clássicos, como Honoré de Balzac e Norbert Elias, foco de nossas reflexões. Os clássicos, segundo Calvino (1993), se constituem como os grandes escritos de formação, que transmitem ensinamentos preciosos para qualquer momento da existência humana. As ideias de diferentes autores, de épocas distintas, resistiram ao tempo na medida em que trataram da essência constitutiva do homem. Com efeito, estudar a história de várias gerações é estudar nossas próprias ideias e ver como chegamos a adquirilas. Importa, pois, nos apropriarmos do legado de homens que olharam para além de si. Estes descobriram o quanto era valioso refletir sobre a organização das sociedades, suas constituições e suas construções como matérias nobres.

Bloch (1965) afirma que a transferência de conhecimento entre as gerações, às vezes até muito afastadas, se dão por meio da oralidade, da imagem e da escrita, possibilitando a continuidade de uma civilização e, por isso, propõe-se uma educação da sensibilidade histórica, uma educação para uma história universal, ampla, total, que pode ser alcançada com o trabalho mútuo dos estudiosos dessa ciência.

Dessa forma, acreditamos que lançar mão da literatura balzaquiana, como fonte que expressa seu tempo histórico se justifica. Como assinala Rónai (1989, p. 12), 
[...] cada obra literária reflete o momento histórico em que foi criada. Além desta relação involuntária com a sua época, a obra de Balzac está fortissimamente ligada a esta por ter-se proposto o romancista, primeiro entre todos, a reproduzir a vida contemporânea com toda a sua riqueza de costumes e de tipos.

Para considerarmos, no entanto, a abordagem do romancista de costumes, a fonte de suas ideias, suas inspirações, os impulsos que recebeu de sua época e os que a esta comunicou, exige do historiador sensibilidade para a interpretação. Além da receptividade emotiva, demanda-se do leitor um desenvolvimento intelectual. Torna-se necessário um diálogo entre o indivíduo-criador, em um tempo distante ou não, com o sujeito-leitor.

Com esse olhar, analisaremos a obra de arte de Balzac, articuladas com a teoria de civilização de Norbert Elias. Como postula Candido (2008, p. 84):

\begin{abstract}
A literatura é, pois, um sistema vivo de obras, agindo umas sobre as outras e sobre os leitores; e só vive na medida em que estes a vivem, decifrando-a, deformando-a. A obra não é produto fixo, unívoco ante qualquer público; nem este é passivo, homogêneo registrando uniformemente o seu efeito. São dois termos que atuam um sobre o outro, e aos quais se junta o autor, termo inicial desse processo de circulação literária, para configurar a realidade da literatura atuando no tempo.
\end{abstract}

A literatura, como outras manifestações artísticas, projeta-se em determinado momento e espaço histórico. Institui-se como expressão de um artista, que só cria a partir das experiências e condições sociais do seu tempo. Logo, traz consigo características econômicas e sociais daquela localidade.

Aceitemos, assim, a legitimidade da literatura balzaquiana. Balzac que, com seu olhar perspicaz, espreitando as palavras e os menores gestos das pessoas, criou o hábito de observar cenas na aparência insignificantes, objetivando perceber germes de conflitos e choques de sentimentos e paixões de seu tempo histórico.

\section{EDUCAÇÃO FEMININA: APROXIMAÇÕES ENTRE A HISTÓRIA DOS COSTUMES DE HONORÉ DE BALZAC E O PROCESSO CIVILIZADOR DE NORBERT ELIAS}

A história dos costumes, de acordo com Elias (1994), está diretamente relacionada às regras de comportamento social. Essa história diz respeito não apenas à questão da etiqueta, mas também se refere à moral, à ética, ao valor interno dos indivíduos e aos aspectos externos que se manifestam nas suas relações sociais. Todas as sociedades, ao longo da história, estabeleceram regulamentos e princípios tendo como fim orientar as relações entre grupos e pessoas.

Segundo Elias (1993), a transformação que ocorre nos costumes condiz com a dinâmica das classes sociais. Quando a classe social superior busca distanciar-se dos outros segmentos sociais, surgem novos padrões de comportamento que, ao longo do tempo, serão adotados pelas demais classes. Para que os modos fossem agradáveis entre seus pares, seriam necessários comportamentos pautados no discernimento entre àqueles que, em geral, agradam ou não as pessoas. Dessa forma, seria possível encontrar os modos que deveriam ser evitados ou adotados no convívio social. Nesse caso, observamos as peculiaridades da formação feminina.

A nosso ver, nesse sentido, o romance de Balzac Memórias de Duas Jovens Esposas, expressa as mudanças nos comportamentos sociais requeridos e construídos pelos homens, com a necessidade de atender às necessidades de seu momento histórico. Essa ideia nos indica que determinados costumes não podem ser naturalizados. Percebemos que o código de conduta espelha a imagem da personalidade em formação, uma direção bem definida, qual seja, a formação do homem. A ideia chave das formulações de Norbert Elias (1993, p. 9) é a tese de que a "[...] condição humana é uma lenta e prolongada construção do próprio homem". Ele entende a civilização como processo, como um civilizar dos costumes. Em suas formulações há uma dimensão ética, pois ele acredita que o homem se civiliza.

Ao pesquisar a obra de Elias, O Processo Civilizador, portanto, almejamos destacar a importância do estudo da história, no sentido de se formar uma consciência nas pessoas, para que entendam a transformação dos homens e de seus hábitos em cada momento histórico, de forma a não naturalizar a educação atual. Os comportamentos foram formados pelos homens, ao longo do tempo, passando por diversas transformações em consonância com as necessidades e objetivos das respectivas sociedades. Elias (1993, p. 263) destaca que:

Se analisamos em sua totalidade esses movimentos do passado, o que vemos é uma mudança em direção bem-definida. Quanto mais profundamente penetramos na riqueza de fatos particulares a fim de descobrir a estrutura e regularidades do passado, mais solidamente emerge um contexto firme de processos dentro dos quais são reunidos os fatos dispersos. Da mesma forma que, no passado, quem observava a natureza, após seguir numerosas hipóteses que em nada deram, gradualmente começou a distinguir uma visão coerente dela tomando forma diante de seus olhos, hoje os fragmentos do passado humano reunidos em nossa mente e em nossos livros pelo trabalho de muitas gerações, começam, aos poucos, a se encaixar num quadro consistente da história e do universo humano em geral. 
Esse excerto nos indica que, para o autor, no presente tanto quanto no passado, existem forças sociais que impulsionam as mudanças para certo fim. O processo civilizador constitui, assim, uma lenta mudança na conduta e sentimentos humanos rumo a uma determinada direção. As conexões entre as classes geram tensões específicas que pressionam no sentido de transformação da sociedade.

Podemos afirmar que são os atos dos homens, nas diversas teias de interdependência, que dão a mudança um caráter universal e produzem, ou não, civilidade. Respondendo às questões de um tempo histórico determinado, Elias (1993, p. 194) enuncia que "[...] planos e ações, impulsos emocionais e racionais de pessoas isoladas constantemente se entrelaçam de modo amistoso ou hostil". Essa rede relacional, resultante das atividades humanas, favoreceram mudanças e modelos que nenhuma pessoa por si só planejou ou criou. Dessa interdependência entre as pessoas se estabelece uma ordem mais forte e mais intensa do que a pretensão e a razão de indivíduos isolados que a compõem. Essa ordem social, de conexão entre impulsos e anelos humanos, definem o movimento configuracional, da mudança histórica e que subjaz ao processo civilizador. Percebemos que, lado a lado com a separação de funções em fluxo, incide a total reestruturação do tecido social.

Dessa forma, torna-se plausível, considerarmos, em linhas gerais, o contexto histórico em que Balzac escreveu o romance que elegemos, para nos aproximarmos do entendimento das mudanças de costumes nas relações entre a aristocracia e a burguesia de seu tempo, ou seja, o período da Restauração (1815-1848). Elias (1993) ressalta, que no século XIX, época em que a monopolização e a centralização de impostos e da força física já estão postos, o conflito entre as classes só seria realizado em virtude das questões econômicas.

Sabe-se que há um consenso entre os leitores e críticos literários que Balzac representa em suas obras o perfil artístico, os anseios, os questionamentos e receios do homem de seu contexto social. Ele retrata a arte, a economia, a política e, enfim, a educação do homem francês.

Honoré de Balzac nasce quando a Revolução Francesa está sendo findada por Napoleão I e uma nova sociedade está se delineando, inclusive em termos geográficos e institucionais. Vejamos como Rémond (1974, p. 126127), descreve esse momento em sua obra $O$ Antigo Regime e a Revolução:

A Revolução não tinha tido tempo para ir além da margem esquerda do Reno e da Itália. Napoleão estende seus domínios até as extremidades da Europa, da península Ibérica à Polônia e das províncias ilíricas até a Dinamarca. Vários estados são anexados à França ou colocados sob sua tutela. O Grande Império, no seu apogeu, em 1810-1811, cobre metade da Europa e a França conta com 130 departamentos. A Europa é profundamente remanejada, suas fronteiras são empurradas e os Estados reagrupados em novos conjuntos. Napoleão leva para toda parte os princípios e instituições revolucionárias; a velha sociedade tradicional das ordens desaparece; o clero e a aristocracia perdem seus privilégios; a servidão é abolida, o homem libertado, a terra emancipada. A burguesia e as classes médias veem abrirem-se para elas novos campos de atividade e de iniciativa. Uma sociedade nova nasceu em todos os países ocupados e administrados pela França.

Balzac assistiu a célebre epopeia napoleônica, bem como suas primeiras derrotas, quando criança. $\mathrm{Na}$ sua juventude, teve a oportunidade de conhecer personagens importantes do Antigo Regime e de participar, efetivamente, dos ideários da Revolução. Balzac vivenciou em seus cinquenta e um anos de vida intensas mudanças.

Segundo Rónai (1989), em toda essa efervescência, o romancista percebe que a “[...] 'liquidação' da Revolução operara-se apenas no domínio político, mas seus germes frutificaram em todos os setores da sociedade", (RÓNAI, 1989, p. 13). Podemos, assim, pontuar as mudanças nos comportamentos sociais. Em grande parte de sua obra $A$ Comédia Humana, Balzac se reporta a inversão de valores morais e suas consequências no interior de instituições sociais importantes para a manutenção da civilidade, como a família e o comportamento humano.

As relações familiares, expressas no romance em pauta, revelam a força do poder e da fortuna. Em função do interesse financeiro, os laços afetivos são reformulados, tanto nas relações aristocráticas quanto nas burguesas. Desse modo, percebemos a formação de uma nova configuração social. Diante da rede das interdependências sociais que ligam os indivíduos uns aos outros, os diferentes grupos se movimentam, adaptam-se às exigências da dinâmica relacional. Durante o período napoleônico, apesar da derrota das antigas instituições - a Nobreza e a Igreja -, observamos o delineamento de um movimento de reconstituição da nobreza, embora, com um novo perfil. A burguesia, vista como força propulsora da transformação social e representante da força popular, acumula bens e riqueza, por meio do desenvolvimento oriundo da indústria e do comércio. Todavia, apenas o sucesso financeiro não lhe permite a entrada efetiva na sociedade aristocrata. $\mathrm{O}$ nível econômico não coincidia com o poder social. A falta de títulos de nobreza e o preconceito aristocrático, que pairava na sociedade em relação às atividades comerciais, faziam com que a burguesia buscasse o reconhecimento moral diante 
da aristocracia. Exatamente por isso tendia a igualarse a nobreza para efetivar seu amplo governo sobre a sociedade. A Nobreza de Espada, por sua vez, queria manter-se como tal, inclusive com seus privilégios, ainda que baseados em novos elementos, em especial, na riqueza do Terceiro Estado. ${ }^{3}$ Considerava-se como o verdadeiro nobre aquele que sustentava sua superioridade por meio do sangue sem se misturar em casamento com pessoas de outros segmentos.

A esse respeito George Lefebvre $(1989$, p. 39) enfatiza que:

A literatura aristocrática, que prosperou no século XVIII ao lado da filosofia burguesa, dedicou-se a fortalecer essa fantasmagoria racial através de uma representação imaginária da nossa história social. Para o conde de Bolainvilliers, os nobres são descendentes dos germanos, que, através da conquista, apossaramse do território dos galo-romanos, inábeis guerreiros temerosos da morte. Trata-se de uma raça diferente, heroica e militar, feita para o comando e preocupada sobretudo com os sinais de respeito que seus direitos honoríficos lhe asseguram. Como poderia ela imaginar ser confundida com o resto da nação?

Para manter, pois, os valores, a fortuna e o nome, em pleno século XIX, a aristocracia era constrangida a tomar atitudes inaceitáveis no século XVI. A Nobreza de Toga foi resultante da troca de favores prestados à coroa, portanto, não era aceita pela Nobreza de Sangue. A primeira, ao contrário dos tradicionais, detinha cargos públicos; portanto, de certa forma, trabalhava e sabia administrar seus bens. Por meio de casamentos ligados aos interesses do dote, foram, aos poucos, se beneficiando com essas uniões. A obra Memórias de Duas Jovens Esposas expõe de maneira clara a situação em que se encontrava a Nobreza, bem como demonstra o perfil da educação feminina.

Essa obra desenrola-se por meio da correspondência de duas jovens nobres, Armanda Luísa Maria de Chaulieu e Renata de Maucombe. Esta última pertencia a uma família nobre empobrecida. As duas, recém-saídas de um convento, ao exporem seus problemas sociais, explicitaram a situação de suas classes. Nessas correspondências revelam-se traços das relações burguesas e aristocráticas, principalmente o comportamento das pessoas e seus laços familiares. Balzac foi fundamental para a composição desse processo civilizador. Como profere Elias (1994, p. 215), abalizado em observações dispersas, supõe-se que ocorreu "[...] mudanças a longo prazo nas emoções e estruturas de controle das pessoas em sociedade particulares - mudanças que se desenvolveram ao longo de uma única e mesma direção durante grande número de gerações". Nos diálogos entre Luíza e Renata, verificamos a ligação entre as estruturas psicológicas individuais (estruturas de personalidade) e as formas tecidas por diversos indivíduos interdependentes (estruturas sociais). Para o autor as estruturas da personalidade e da sociedade se desenvolvem de forma indissolúvel.

Vejamos, nesse sentido, um trecho da carta de Renata (já senhora de l'Estorade) para a senhorita de Chaulieu, na qual ela explicita que seu casamento com um burguês asseguraria o seu futuro e de sua família. Ela pretendia enobrecer a família burguesa de seu esposo, Luís de l'Estorade. Assim, era necessário seguir o protocolo aristocrático.

O velho pai não é mais avaro, [...] para me ser agradável adotou os costumes, as maneiras do tempo presente. Temos cavalos ingleses, um cupê, uma caleça e um tílburi. Nossos empregados têm um fardamento simples, porém elegante. Por isso tudo, somos tidos como pródigos. Emprego minha inteligência (não estou rindo) a dirigir a casa com economia, a proporcionar a maior soma de prazeres pelo menor custo possível. Já demonstrei a Luís a necessidade de abrir estradas, a fim de lhe conquistar a reputação de homem preocupado pelo bem da localidade. Obrigo-o a completar sua educação. Espero vê-lo, em breve, membro do conselho geral do seu departamento, por influência da minha família e da de sua mãe. [...] ele deveria fazer-se eleger deputado do departamento nas próximas eleições; minha família auxiliaria sua candidatura e nós teríamos, então, o prazer de passar os invernos em Paris (BALZAC, 1989, p. 249).

Percebemos, nesse excerto, quais seriam os quesitos relevantes para inserir-se na sociedade aristocrática. $\mathrm{O}$ pai de Renata, conhecedor da riqueza acumulada por intermédio da avareza do barão de l'Estorade, aceitou o pedido de casamento, sem desembolsar dote algum, pelo contrário, receberia uma considerável parte da fortuna. Vemos ainda que o próprio Barão, que sempre viveu na avareza, comendo com seus empregados para acumular tostões, dá à nora liberdade plena para gastar, desde que isso traga prestígio e respeito a seu filho, por conseguinte, para seu nome.

Em relação à Luísa, verificamos que sua mãe percebe a necessidade de sua filha ser educada para viver em sociedade: “[...] Embora eu queira deixá-la completamente livre, creio que nos primeiros tempos andará acertada se ouvir os conselhos de uma mãe que procederá consigo como uma irmã” (BALZAC, 1989, p. 203). Luísa precisava seguir todo um ritual para se ingressar ao meio aristocrático, distinguindo-se da nobreza de toga. Sua mãe lhe ensina as normas da toalete, o vestuário conveniente, a linguagem e gestos adequados, enfim, elementos indispensáveis para conviver com seus pares. Para tanto, demandava-se um ensinamento, um 
fim explícito. Os hábitos diários de sua mãe denotavam situações de aprendizagem condizentes ao seu tempo.

Minha mãe veste-se, nunca é visível das duas horas às quatro: às quatro sai para um passeio de uma hora; recebe das seis às sete, quando não janta fora; depois a noite é preenchida pelos divertimentos, espetáculos, bailes, concertos, visitas. Enfim, sua vida é tão cheia de ocupações que julgo não ter ela um quarto de hora seu. Deve passar um tempo considerável na sua toilette matinal, pois, está divina ao almoço, que se realiza entre onze horas e meio dia [...]. (BALZAC, 1989, p. 208).

Existia, portanto, uma etiqueta a ser seguida entre a nobreza. Luísa, com comportamentos diferenciados por sua vivência em um convento, teria que adquirir novos hábitos, novos costumes, que deveria discernir entre corretos ou não, aceitáveis ou não na sociedade aristocrática. Isso lhe causava ansiedades. Assim, Luísa escreve à Renata:

[...] ainda não pus o pé fora de casa, não conheço nada, estou à espera de ser desasnada, de que a minha toilette e o meu ar estejam em harmonia com essa sociedade, cuja agitação me assombra, embora não lhe ouça o rumor, [...]. Estou começando a destruir os hábitos do convento para adquirir os da vida mundana (BALZAC, 1989, p. 208).

Para poder frequentar as altas esferas sociais Luísa precisou obter os conhecimentos veiculados pela sociedade aristocrata. Tudo aquilo que parecia natural na mãe precisava ser aprendido pela filha. Era imprescindível comportar-se conforme ditava as regras de conduta de seu meio social, nesse caso, o aristocrata. O comportamento social necessitava de polidez, de etiqueta e requinte. Consideramos seu relato, nesses termos:

[...] querida, tudo está em harmonia: um andar, uma voz! A gente se lembra dos meneios da saia da avó, que nunca a tocava: enfim, sou bela e graciosa. De acordo com a minha fantasia poderei rir como rimos tantas vezes, e serei respeitada: haverá não sei o que de imponente nas covinhas que o Gracejo com seus dedinhos leves cavara nas minhas alvas faces. Posso baixar os olhos e dar-me um coração de gelo sob minha fronte de neve. Posso ostentar o pescoço melancólico do cisne, tomando uma atitude de madona, e as virgens desenhadas pelos pintores estarão cem furos abaixo de mim; estarei mais alto do que elas no céu. Para me falar, um homem ver-se-á obrigado a musicalizar a voz. [...] tenho um enxoval de noiva! Tudo está perfeitamente arrumado, perfumado, nas gavetas de cedro e de frente laqueada do delicioso gabinete de toilette. Tenho fitas, calçados, luvas, tudo em profusão. Meu pai deu-me graciosamente o que requer uma moça: um nécessaire, uma toilette, uma caçoila, um leque, uma sombrinha, um livro de orações, uma corrente de ouro, um xale de cachemira; prometeu mandar ensinar-me a montar a cavalo. Enfim, sei dançar! Amanhã, sim, amanhã à noite, serei apresentada (BALZAC, 1989, p. 211-212).

Vemos, nessas relações sociais, um passo na direção da civilização. Concomitantemente, às mudanças nas configurações da sociedade, modificavam, também, as estruturas da personalidade das pessoas. Luísa, enfim, estava preparada para frequentar salões, teatros, óperas e bailes. Aconteceu com Luísa o que Elias (1993) defende como rede de dependência civilizatória:

[...] a rede de dependências que se cruzam no indivíduo tornou-se mais ampla e mudou de estrutura; [...], numa correspondência exata com essa estrutura, a modelação do comportamento e de toda vida emocional, a estrutura da personalidade, mudou também. O processo 'civilizador' visto a partir dos aspectos dos padrões de conduta e de controle de pulsões é a mesma tendência que, se considerada do ponto de vista das relações humanas, aparece como um processo de integração em andamento, um aumento na diferenciação de funções sociais e na interdependência e como a formação de unidades ainda maiores de integração, de cuja evolução e fortuna o indivíduo depende, saiba disso ou não (ELIAS, 1993, p. 83).

Segundo o autor, as funções sociais distinguiramse cada vez mais. Quanto mais diferenciadas elas se tornavam, mais crescia o número delas e, assim, de pessoas das quais o indivíduo constantemente dependia em todas suas ações. Elias (1993, p. 196) afiança que a configuração social "[...] tornou-se tão complexa e extensa, o esforço necessário para comportar-se 'corretamente' dentro dela ficou tão grande que, além do autocontrole consciente do indivíduo, um cego aparelho automático de autocontrole foi firmemente estabelecido".

Nesses termos, no tocante às mudanças na estrutura da personalidade, segundo Elias (1993), outro fator importante seria o autocontrole, que passa a ter uma função cada vez mais relevante, ao mesmo tempo em que diminui a necessidade de um controle externo. Entendemos o autocontrole como fruto do processo educacional e civilizatório. No decorrer do processo de civilização ocorre uma alteração no equilíbrio entre o controle externo e o autocontrole, favorecendo este último.

Percebe-se, pois, no ambiente aristocrático, a necessidade da mulher assumir uma conduta que lhe propiciasse sucesso em suas relações sociais. Além de apresentar-se adequadamente, a ela incumbia-se discernimento em como agir mediante determinadas 
situações. Deveria, então, conter suas pulsões, evitando manifestar uma opinião negativa acerca da sociedade. Assim, ensina a senhora de Chaulieu a sua filha Luísa: "[...] o bom gosto consiste tanto no conhecimento das coisas que se devem calar como nas que se devem dizer" (BALZAC, 1989, p. 215). Era-lhe permitido somente no reduto familiar expor suas ideias sem correr o risco de ser criticada. Aconselha ainda sua mãe: “[...] - Em família [...] pode falar sem receio" (BALZAC, 1989, p. 227). Se essas opiniões são expostas sem critério e de maneira desmedida, a mulher corre o risco de ser negligenciada pela sociedade. A mulher deve se portar, por conseguinte, de forma sutil e dissimulada, não expondo explicitamente o pensamento e o conhecimento.

Verificamos que Balzac descreve a história dos costumes, que aos poucos foram se internalizando pelo hábito. Ele demonstra as mudanças das regras sociais e o modo como o indivíduo as percebia, modificando seus comportamentos e sentimentos.

O diálogo de Luísa com seu pai, nesse sentido, nos apontam algumas mudanças de comportamento, que ocorreram em consequência do movimento da dinâmica autônoma das relações sociais, em que os homens eram constrangidos a conviver.

A França, minha filha, está numa situação precária que só é conhecida pelo rei e alguns espíritos elevados; mas o rei é uma cabeça sem braços; além disso, os grandes espíritos que partilham o segredo do perigo não têm nenhuma autoridade sobre os homens que devem ser utilizados para se chegar a um resultado feliz. Esses homens, vomitados pela eleição popular, não querem ser instrumentos. Por mais notáveis que sejam, continuam a obra de destruição social, [...]. O rei é um grande espírito, vê as coisas claras; mas, dia a dia, conquistado pelos adeptos do irmão, que querem ir demasiado depressa, ele não tem dois anos de vida, e esse moribundo arranja as suas cobertas para morrer tranqüilo. [...]. Ao cortar a cabeça de Luís XVI, a Revolução cortou a cabeça de todos os chefes de família. Hoje não há mais família, há somente indivíduos. [...]. Achamo-nos entre dois sistemas: ou construir o Estado pela família, ou constituí-lo pelo interesse pessoal: a democracia ou a aristocracia, a discussão ou a obediência, o catolicismo ou a indiferença religiosa, eis a questão em poucas palavras. Pertenço ao pequeno número dos que querem resistir ao que se denomina povo, no próprio interesse deste. Não se trata mais de direitos feudais, como se diz aos ingênuos, nem de fidalguia; trata-se do Estado, tratase da vida da França. Todo país que não se baseia no poder pátrio fica sem existência assegurada. Aí começa a escala das responsabilidades, e a subordinação que ascende até o rei. O rei somos nós todos! (BALZAC, 1989, p. 237-238).
Este importante discurso do senhor de Chaulieu, com a intenção de convencer sua filha a renunciar a herança da avó em favor do irmão para que este constituísse um morgadio, ${ }^{4}$ nos insere ao contexto das lutas políticas que então se travavam. A visão política desse aristocrata manifesta sua inquietação com o estabelecimento da democracia. Temia-se que o Estado sucumbisse na desordem após a Revolução, desencadeando uma luta por interesses pessoais e não nacionais.

Averiguamos essa política também em relação à Renata que tinha como meta enobrecer seu esposo e seu sogro. Vejamos esse intento, então, nas palavras da então baronesa de Macumer (Luísa) para a futura condessa de l'Estorade, pois ainda não havia se casado com Luís de l'Estorade:

Ouve: adivinhei que te tornaste ambiciosa sob o nome de Luís de l'Estorade; pois bem, nas próximas eleições, faze com que ele seja eleito deputado, porque ele terá cerca de quarenta anos e, como a Câmara não se reunirá senão dentro de seis meses depois das eleições, ele estará então precisamente com a idade requerida para ser um homem político. Virás a Paris, não te digo mais nada. Meu pai e os amigos que vou granjear vos apreciarão e se teu velho sogro quiser constituir um morgadio, obteremos para Luís o título de conde (BALZAC, 1989, p. 294-295).

Neste excerto Balzac, se posicionando em defesa dos interesses aristocráticos, nos faz reportar ao pensamento de Elias (1993). O autor destaca que, em ajuste com o processo civilizador, a movimentação “[...] cega dos homens, entremisturando-se em atos e objetivos, gradualmente leva [...] para a intervenção planejada nas estruturas social e individual [...] baseada num conhecimento cada vez maior da dinâmica nãoplanejada dessas estruturas" (ELIAS, 1993, p. 195). Este, pois, se constitui como mecanismo do movimento das lutas sociais: os distintos segmentos sociais convivendo entre si ou sobrepondo-se uns aos outros conforme suas necessidades.

Nessas condições, Elias (1993, p. 214) conclui que a

[...] nobreza de corte, a vanguarda da 'civilité', foi gradualmente compelida a exercer um rigoroso controle das emoções e uma precisa modelação de sua conduta, através de sua crescente integração na rede de interdependências, representada neste caso pela pinça formada pela monarquia e burguesia, na qual estava aprisionada a nobreza [...] o autocontrole a ela imposto por sua função e situação serviu ao mesmo tempo como valor de prestígio, como meio de distinguir-se dos grupos inferiores que a fustigavam e ela tudo fez para impedir que essas diferenças fossem apagadas. 
Nota-se, assim, que hábitos individuais lentamente se firmaram, originando um comportamento específico que buscava um controle das emoções condizentes ao tecido social. Esses novos padrões de comportamento, pouco a pouco, deixam de ser conscientes para transformarem-se em uma segunda natureza, e é a essa natureza que o autor se refere quando menciona as mudanças na estrutura da personalidade.

$\mathrm{Na}$ medida em que atos diferenciados acrescem e a rede de interdependência entre os indivíduos se acentuam, torna-se mais firme o hábito de prever as consequências de longo prazo. Segundo Elias (1993) as duas formas de previsibilidade das ações são por ele denominadas de psicologização e racionalização. Cada vez mais as funções mentais conscientes desenvolvem-se em direção à racionalização, menos influenciadas por impulsos emocionais.

Ressaltamos, assim, que as trajetórias dos processos civilizadores abarcam a ampliação da distinção entre instintos e domínio dos instintos, o aumento da coação pelo desenvolvimento da previsibilidade, o avanço na fronteira entre vergonha e repugnância, no ajuste de comportamentos e contrastes emocionais.

Balzac, enfim, identificou os traços mais característicos das mudanças dos costumes de sua época e conseguiu entender sua multiplicidade. No romance analisado observamos a trajetória que a educação feminina foi tomando. Esse literato se dedica aos costumes, à vida privada; divide seu objeto de observação, avaliando cada um, mas, ao mesmo tempo, interligando cada objeto de análise ao todo do conjunto social. Como indica Rónai (1989, p. 22), Balzac “[...] no decorrer de sua vida, teve de 'viver' a sociedade moderna antes de revivê-la, em toda a sua complexidade, no papel”. Ele viveu as condições sociais, econômicas e políticas que provocaram mudanças no seu lócus. Balzac, na A Comédia Humana, nos dá a história da sociedade francesa apresentando "[...] de 1816 a 1848, a pressão cada vez maior que a burguesia ascendente exercia sobre a nobreza que se constituíra depois de 1815 e que, [...] levantava outra vez a bandeira da vieille politesse française", (RÓNAI, 1989, p. 39).

\section{CONSIDERAÇÕES FINAIS}

Constatamos que as transformações sociais do momento histórico de Balzac foram registradas de muitas maneiras, inclusive na arte. O desafio lançado por Balzac e outros grandes romancistas do século XIX para a história, seria o tratamento da vida privada e dos costumes em suas narrativas. A eleição da literatura como fonte para nosso trabalho, explicita nosso entendimento de que, por meio da sensibilidade do artista, das mudanças nos comportamentos das pessoas, na complexidade da rede social na sua totalidade, indubitavelmente apreendemos os processos educativos de uma dada época. Assim, procuramos, por intermédio da visão aguçada de Balzac, perceber o processo civilizador nas relações sociais, como resposta às necessidades vigentes, para se viver ou se manter socialmente integrado. $\mathrm{O}$ enfrentamento entre as partes que compõem a sociedade, os diferentes interesses pessoais interferem e modificam a vida da sociedade ao todo.

A análise do romance de Balzac amalgamada ao processo civilizador de Norbert Elias nos oportunizou a compreensão da forma como as transformações sociais ocorrem ao longo do tempo e perceber que determinadas condutas e instituições sociais são construções humanas e que não devem ser naturalizadas.

Entendemos que os comportamentos e os conhecimentos existentes passam por constantes alterações, em função da capacidade dos homens se influenciarem mutuamente. Há um ato educativo entre os homens. A capacidade de os homens reagirem, de serem capazes de atuar junto a outros homens, aprendendo e ensinando, torna possível a educação.

Nesse processo educacional, aos poucos, cada indivíduo compreende sua posição no conjunto social e adota as atitudes socialmente julgadas adequadas, assimilando os hábitos correspondentes. Assim, este estudo nos oportunizou compreender e identificar como se desenvolveu aspectos da educação feminina da França da Restauração, bem como os agentes envolvidos, os valores assimilados e a influência da mulher nessa sociedade. A educação das protagonistas Armanda Luísa Maria de Chaulieu e Renata de Maucombe nos revela que a mulher aprende, no convívio familiar e social, certos comportamentos necessários para assumir determinados papeis na sociedade. Para conviver em sociedade, a mulher tem que aprender a comportar-se conforme determina as regras de conduta estipulados por seu meio social, no caso em tela, o aristocrata.

Consideramos, pois, que o conhecimento que os sujeitos construíram é que tornou possível a convivência entre eles, ou seja, com base na educação, eles formaram a sociedade em que vivem: suas instituições, crenças, filosofia, arte e ciência.

Nesse sentido, a linguagem literária, como construção de conhecimento, necessita, para a intelecção de sua sistematização, que o sujeito desenvolva certas competências que o auxiliem a sentir e a significar o texto. Acreditamos que o olhar e o gosto podem ser transformados pelo conhecimento, pois compactuamos da ideia de quanto mais se conhece mais se pode apreciar o belo. Essa sensibilidade pode resultar ao ser humano maior entendimento de sua realidade histórica e social, das inquietações e indagações de sua temporalidade. Por 
meio do conhecimento, o homem toma consciência do papel que deve desempenhar na sociedade, contribuindo, por sua vez, seja para a transformação dessa sociedade, seja para a sua preservação e desenvolvimento humano. Entendemos, nessas condições, que a compreensão do mundo pode dar-se pelo entendimento da arte literária, para tanto, a sensibilização humana é imprescindível.

\section{REFERÊNCIAS}

ARISTÓTELES. Ética a Nicômaco. Brasília: Editora da UnB, 1985.

BALZAC, Honoré de. Memórias de Duas Jovens Esposas. In: BALZAC, Honoré de. A comédia humana. São Paulo: Globo, 1989. v. I.

BLOCH, Marc Leopold Benjamin. Introdução à História. Lisboa: Publicações Europa-América, 1965.

BURNS, Edward Mcnall. História da civilização ocidental. São Paulo: Globo, 1974. v. II.

CALVINO, Ítalo. Porque ler clássicos? São Paulo: Companhia das Letras, 1993.

CANDIDO, Antonio. Vários Escritos. São Paulo: Duas Cidades, 1995.

CANDIDO, Antonio. Literatura e Sociedade. Estudos de teoria e história literária. Rio de Janeiro: Ouro sobre Azul, 2008.

CASTRO, Hebe. História social. In: CARDOSO, Ciro Flamarion; VAINFAS, Ronaldo (Org.). Domínios da história: ensaios de teoria e metodologia. Rio de Janeiro: Campus, 1997.

ELIAS, Norbert. O processo civilizador. Rio de Janeiro: Jorge Zahar Editor, 1993. v. II.

ELIAS, Norbert. O processo civilizador. Rio de Janeiro: Jorge Zahar Editor, 1994. v. I.

ELIAS, Norbert. A sociedade de corte. Rio de Janeiro: Jorge Zahar Editor, 2001.

LEFEBVRE, George. O surgimento da Revolução Francesa. Rio de Janeiro: Paz e Terra, 1989.
RÉMOND, René. O antigo regime e a revolução. 1715-1815. São Paulo: Cultrix, 1974.

RIBEIRO, Renato Janine. Apresentação a Norbert Elias. In: ELIAS, Norbert. O processo civilizador. Rio de Janeiro: Jorge Zahar Editor, 1994. v. I.

RÓNAI, Paulo. A vida de Balzac. In: BALZAC, Honoré de. A comédia humana. São Paulo: Globo, 1989. v. I.

\section{Notas}

1 Divide-se em três partes: Estudos de Costumes (vol. I ao XIV), Estudos Filosóficos (vol. XV ao XVII) e Estudos Analíticos (vol. XVII). A maior delas, a dos Estudos de Costumes subdivide- se em seis cenas, chegando ao total de setenta e três romances.

2 De acordo com Norbert Elias (2001) a Nobreza de Espada seria a tradicional, destinada à carreira militar, condição adquirida por nascimento. A Nobreza de Toga era composta por aqueles segmentos burgueses que ascenderam à corte por meio da compra de cargos públicos, por concessão dos monarcas e pelo exercício das funções burocráticas.

3 Segundo Burns (1959), o Terceiro Estado seria a ordem de pessoas que foi o instrumento da revolução de 1789. Este era formado pelos camponeses, trabalhadores das cidades, desempregados, marginais (formavam o grupo dos sans-culottes, nome dado aos pobres urbanos) e a burguesia. O Primeiro Estado era o Clero e o Segundo Estado era a Nobreza.

4 "O sistema dos morgadios, abolido pela Revolução Francesa, foi restabelecido em 1806 por Napoleão I, o qual, para aumentar o brilho do Império, instituiu uma nova nobreza. $\mathrm{O}$ morgadio (em francês: majorat) era uma propriedade cujas rendas eram especialmente destinadas, em virtude de uma autorização do soberano, a sustentar um título nobiliárquico e a serem transmitidas perpetuamente na linha masculina por ordem de primogenitura. Havia duas espécies de morgadio: uma, chamada morgadio 'de movimento próprio', constituída por uma dotação do próprio chefe do Estado; outra, 'a pedido', que um chefe de família estava autorizado a constituir à custa de seus próprios bens, vinculando parte de suas propriedades como 'dotação' de um título hereditário. Os títulos - duque, conde, barão, visconde, barão - da nova aristocracia, criada pelo imperador, não se tornavam hereditariamente transmissíveis senão por meio da constituição de um morgadio. A renda obrigatória dos morgadios foi fixada por decreto: era tanto maior quanto mais elevado o título. A Restauração manteve este sistema e até obrigou os membros da Câmara dos Pares a instituírem morgadios. A partir da Revolução de julho de 1830 o sistema dos morgadios foi progressivamente abolido" (BALZAC, 1989, p. 295).

Artigo recebido em maio 2013.

Aprovado em abril 2014. 